\title{
Ruscogenin Protects against High-Fat Diet-Induced Nonalcoholic Steatohepatitis in Hamsters
}

Authors

Affiliations

\author{
Hung-Jen Lu ${ }^{1}$, Shorong-Shii Liou ${ }^{2}$, Chia Ju Chang ${ }^{2}$, Sheng Da Lin ${ }^{2}$, Cheng Yang ${ }^{2}$, Ming-Chang Wu ${ }^{1}$, I-Min Liu ${ }^{2}$
}

${ }^{1}$ Department of Food Science, College of Agriculture, National Pingtung University of Science and Technology, Neipu Township, Pingtung County, Taiwan, ROC

2 Department of Pharmacy \& Graduate Institute of Pharmaceutical Technology, Tajen University, Yanpu Township, Pingtung County, Taiwan, ROC

\author{
Key words \\ - fatty acid $\beta$-oxidation \\ - inflammatory cytokines \\ - lipogenic gene \\ - nonalcoholic steatohepatitis \\ - ruscogenin
}

\section{Abstract \\ $\nabla$}

The protective effects of ruscogenin on nonalcoholic steatohepatitis in hamsters fed a high-fat diet were investigated. Ruscogenin $(0.3,1.0$, or $3.0 \mathrm{mg} / \mathrm{kg} /$ day) was orally administered by gavage once daily for eight weeks. A high-fat diet induced increases in plasma levels of total cholesterol, triglycerides, and free fatty acids, while the degree of insulin resistance was lowered by ruscogenin. High-fat diet-induced hepatic steatosis and necroinflammation were improved by ruscogenin. Gene expression of inflammatory cytokines and activity of nuclear transcription factor- $k$ B were

\section{Introduction}

\section{$\nabla$}

Nonalcoholic fatty liver disease (NAFLD) is defined as the accumulation of liver fat exceeding $5 \%$ of hepatocytes in the absence of significant alcohol intake (significant alcohol intake being defined as $20 \mathrm{~g} / 10 \mathrm{~g}$ per day for men/women, respectively) or other specific etiology [1]. Nonalcoholic steatohepatitis (NASH), the extreme form of NAFLD, is characterized by an increase in fat deposition, fibrosis, oxidative stress, and chronic inflammation in the liver [2]. It is also a common cause of cirrhosis and could later progress to hepatocellular carcinoma [3]. A "multi-hit" theory has been proposed to depict the key pathogenic processes of NASH development. In this theory, obesity and insulin resistance is thought to be the "first hit" to the liver because it induces a net accumulation of lipid in hepatocytes which may cause the occurrence of following "hits", such as oxidative stress, inflammation, fibrosis, and apoptosis [4]. Therapies that limit hepatic injury and the related occurrence of inflammation and fibrosis are particularly appealing for this condition. Ruscogenin $\quad[(1 \beta, 3 \beta, 25 R)$-spirost-5-en-1,3-diol; - Fig. 1], first isolated from Ruscus aculeatus, is also increased in the high-fat diet group, which were attenuted by ruscogenin. Ruscogenin decreased hepatic mRNA levels of sterol regulatory element-binding protein-1c and its lipogenic target genes. The hepatic mRNA expression of peroxisome proliferator-activated receptor $\alpha$, together with its target genes responsible for fatty acid $\beta$ oxidation were upregulated by ruscogenin. In conclusion, these findings suggest that ruscogenin may attenuate high-fat diet-induced steatohepatitis through anti-inflammatory mechanisms, reducing hepatic lipogenic gene expression, and upregulating proteins in the fatty acid oxidation process. also a major steroidal sapogenin of the traditional Chinese herb Radix Ophiopogon japonicus, which has been clinically used for a long time to treat acute and chronic inflammatory and cardiovascular diseases [5]. In Chinese medicine, Radix Ophiopogon japonicus is the cardinal herb for yin deficiency. According to the Chinese Herbal Medicine Materia Medica, the herb is sweet, slightly bitter and slightly cold, enters the heart, lungs and stomach channels, and nourishes the yin of the stomach, spleen, heart and lungs, clears heat, and quiets irritability [6]. Ruscogenin acts as an elastase inhibitor, decreases capillary permeability, and is widely used to treat chronic venous insufficiency and vasculitis $[7,8]$. It has been previously found to exert significant antithrombotic activity, and the possible mechanism of ruscogenin could be attributed to its inhibition of intercellular adhesion molecule-1 upregulation via nuclear factor (NF)- $k$ B p 65 translocation induced by tumor necrosis factor (TNF)- $\alpha[9,10]$. It was also found that ruscogenin significantly attenuated lipopolysaccharide-induced acute lung injury in a model with mice, which was possibly linked to the inhibition of NF- $k$ B activation [11]. Such activities of ruscogenin indicate its potential protec- 


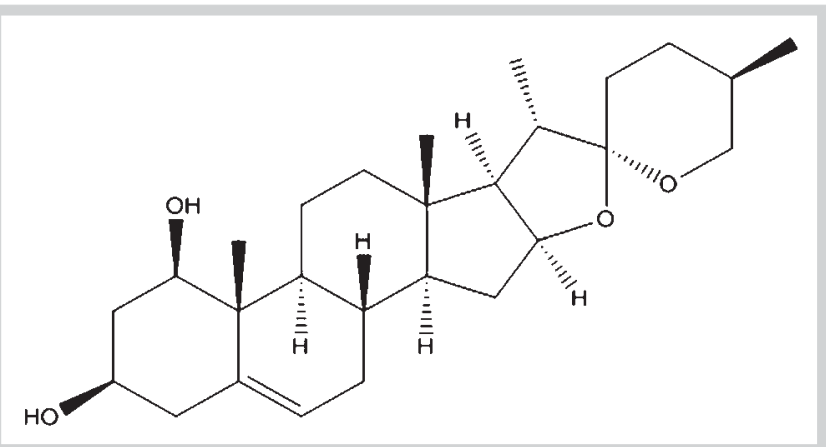

Fig. 1 Structure of ruscogenin.

tion in NAFLD/NASH-induced hepatic injury; however, there is no report about it until now. The present study was designed to explore the effects of ruscogenin in treating high-fat diet (HFD)induced steatohepatitis and its possible mechanisms.

\section{Results}

At the end of eight weeks of treatment, the body weight, visceral fat, and relative liver weights in HFD-fed hamsters were significantly higher than those in the normal diet (ND)-fed group ( $\bullet$ Table 1). High doses of ruscogenin (3.0 mg/ $/ \mathrm{kg} /$ day) suppressed body weight gain. The relative weights of the liver, epididymal adipose tissue, and perirenal adipose tissue were significantly lower in ruscogenin ( $3.0 \mathrm{mg} / \mathrm{kg} / \mathrm{day})$-supplemented groups than those in the HFD-fed group ( Table 1). Similar results were seen in HFD-fed hamsters treated with fenofibrate ( Table 1). No significant differences in daily food or water intake were observed between the groups over the experimental period ( Table 1). Plasma alanine aminotransferase (ALT) and aspartate aminotransferase (AST) activities in HFD-fed hamsters were higher than those in the ND-fed group ( Table 1). The ALT and AST activities were markedly reduced in HFD-fed hamsters treated for eight weeks with a high dose $(3.0 \mathrm{mg} / \mathrm{kg} /$ day) of ruscogenin ( $\bullet$ Table 1 ).

The HFD caused elevated concentrations of plasma total cholesterol (TC), triglycerides (TG), and low-density lipoprotein cholesterol (LDL-C). Oral administration of ruscogenin at a dose of 0.3 , 1.0 , or $3.0 \mathrm{mg} / \mathrm{kg} /$ day significantly reduced plasma TC levels (22.8\%, 31.4\%, and 39.7\% reduction, respectively; $\odot$ Fig. $2 \mathrm{~A})$. All doses of ruscogenin decreased plasma TG levels in HFD-fed hamsters; the reduction of plasma TG induced by ruscogenin at $3.0 \mathrm{mg} / \mathrm{kg} /$ day was nearly $32.1 \%$ ( Fig. $2 \mathrm{~A}$ ). Ruscogenin at an oral dose of $0.3,1.0$, or $3.0 \mathrm{mg} / \mathrm{kg} /$ day significantly reduced total plasma LDL-C levels (32.1\%, 42.2\%, and 52.8\% reduction, respectively) compared to that of vehicle-treated HFD-fed hamsters ( Fig. 2A). Plasma TC, TG, and LDL-C concentrations were reduced significantly by $46.7 \%, 37.8 \%$, and $60.4 \%$, respectively, in fenofibrate-treated HFD-fed hamsters compared with vehicletreated HFD-fed hamsters ( $\bullet$ Fig. $2 \mathrm{~A}$ ).

The plasma concentration of high-density lipoprotein cholesterol (HDL-C) in HFD-fed hamsters was reduced to $60.4 \%$ of the level observed in the ND-fed group ( Fig. 2A). After eight weeks of treatment with ruscogenin $(3.0 \mathrm{mg} / \mathrm{kg} /$ day $)$ or fenofibrate, the plasma HDL-C concentration in HFD-fed hamsters was elevated to nearly that of the ND-fed group ( $\odot$ Fig. $2 \mathrm{~A}$ ).

Plasma free fatty acid (FFA) levels in vehicle-treated HFD-fed hamsters were about 2.0-fold of that observed in the ND-fed group ( Fig. 2A). The plasma FFA levels decreased by $38.1 \%$ in HFD-fed hamsters treated with ruscogenin $(3.0 \mathrm{mg} / \mathrm{kg} /$ day $)$ compared to their vehicle-treated counterparts ( Fig. 2A). Fenofibrate treatment reduced FFA concentrations in HFD-fed hamsters by $38.3 \%$ relative to the level in vehicle-treated HFD-fed hamsters (० Fig. 2A).

The hepatic TC level was significantly higher in HFD-fed hamsters than in hamsters from the ND-fed group, which was reduced by $37.2 \%$ in HFD-fed hamsters treated with ruscogenin $(3.0 \mathrm{mg} / \mathrm{kg} /$ day; Fig. 2 B). Ruscogenin treatment ( $3.0 \mathrm{mg} / \mathrm{kg} /$ day) also produced a significant reduction in the hepatic TG concentration by $27.2 \%$ of that in the vehicle-treated HFD-fed hamsters ( Fig. 2 B). Hepatic TC and TG levels were significantly reduced (by $44.5 \%$

Table 1 The effects of treatments on body weight (BW), liver and visceral fat weight, feeding behaviors, and plasma transaminase activity of hamsters.

\begin{tabular}{|c|c|c|c|c|c|c|}
\hline & \multirow{3}{*}{$\begin{array}{l}\text { ND-fed } \\
\text { Vehicle }\end{array}$} & \multicolumn{5}{|l|}{ HFD-fed } \\
\hline & & \multirow[t]{2}{*}{ Vehicle } & \multicolumn{3}{|c|}{ Ruscogenin (mg/kg/day) } & \multirow{2}{*}{$\begin{array}{l}\text { Fenofibrate } \\
(100 \mathrm{mg} / \mathrm{kg} / \text { day }\end{array}$} \\
\hline & & & 0.3 & 1.0 & 3.0 & \\
\hline Initial BW (g) & $93.86 \pm 3.52$ & $94.12 \pm 2.98$ & $93.71 \pm 3.07$ & $92.82 \pm 2.78$ & $93.64 \pm 4.11$ & $93.42 \pm 3.62$ \\
\hline Final BW (g) & $227.33 \pm 8.26^{c}$ & $301.02 \pm 7.42^{\mathrm{a}}$ & $285.21 \pm 6.33^{a}$ & $279.32 \pm 7.09^{a}$ & $260.35 \pm 6.12^{a, c}$ & $246.13 \pm 7.83^{a, c}$ \\
\hline $\begin{array}{l}\text { Epididymal WAT } \\
\text { (mg/100 g BW) }\end{array}$ & $161.92 \pm 18.26^{d}$ & $242.39 \pm 20.31^{b}$ & $233.47 \pm 17.82^{b}$ & $207.85 \pm 16.29^{\mathrm{a}, \mathrm{c}}$ & $173.69 \pm 17.37^{d}$ & $167.58 \pm 15.33^{d}$ \\
\hline $\begin{array}{l}\text { Perirenal WAT } \\
(\mathrm{mg} / 100 \mathrm{~g} \mathrm{BW})\end{array}$ & $80.72 \pm 6.41^{c}$ & $111.43 \pm 7.32^{\mathrm{a}}$ & $101.12 \pm 7.23^{a}$ & $88.84 \pm 8.16^{c}$ & $86.36 \pm 7.32^{c}$ & $84.17 \pm 8.08^{c}$ \\
\hline $\begin{array}{l}\text { Mesenteric WAT } \\
(\mathrm{mg} / 100 \mathrm{~g} \mathrm{BW})\end{array}$ & $75.27 \pm 5.26^{c}$ & $104.25 \pm 6.17^{a}$ & $94.82 \pm 4.38^{\mathrm{a}}$ & $87.32 \pm 5.17 c$ & $81.24 \pm 6.21^{c}$ & $77.39 \pm 5.86^{c}$ \\
\hline $\begin{array}{l}\text { Hepatic weight coeffi- } \\
\text { cient }(\mathrm{g} / 100 \mathrm{~g} \mathrm{BW})\end{array}$ & $4.81 \pm 0.83$ & $5.83 \pm 0.76$ & $5.62 \pm 0.61$ & $5.23 \pm 0.69$ & $5.17 \pm 0.53$ & $4.91 \pm 0.66$ \\
\hline Food intake (g/day) & $10.16 \pm 1.76$ & $11.05 \pm 1.83$ & $10.76 \pm 1.97$ & $10.96 \pm 1.58$ & $9.92 \pm 1.64$ & $10.08 \pm 2.01$ \\
\hline Water intake (mL/day) & $12.78 \pm 4.83$ & $13.16 \pm 5.68$ & $12.87 \pm 6.11$ & $13.11 \pm 5.87$ & $13.06 \pm 4.36$ & $12.97 \pm 5.26$ \\
\hline Plasma ALT (U/L) & $52.61 \pm 7.13^{d}$ & $334.05 \pm 15.17^{b}$ & $276.31 \pm 12.33^{b, c}$ & $200.49 \pm 11.86^{b, c}$ & $138.28 \pm 9.12^{\mathrm{a}, \mathrm{d}}$ & $95.24 \pm 6.13^{\mathrm{a}, \mathrm{d}}$ \\
\hline Plasma AST (U/L) & $121.27 \pm 9.38^{d}$ & $489.32 \pm 18.73^{b}$ & $406.35 \pm 17.42^{b, c}$ & $294.85 \pm 18.26^{\mathrm{b}, \mathrm{c}}$ & $218.21 \pm 19.37^{\mathrm{a}, \mathrm{d}}$ & $175.42 \pm 10.86^{\mathrm{a}, \mathrm{d}}$ \\
\hline
\end{tabular}

The vehicle (distilled water) used to prepare the tested medication solution was given at the same volume. Values (mean $\pm S$. D.) were obtained from each group of eight animals after eight weeks of the experimental period. ${ }^{a} \mathrm{P}<0.05$ and ${ }^{\mathrm{b}} \mathrm{P}<0.01$ compared to vehicle-treated ND-fed hamsters in each group, respectively. ${ }^{\mathrm{c}} \mathrm{P}<0.05$ and ${ }^{\mathrm{d}} \mathrm{P}<0.01$ compared to vehicle-treated HFD-fed hamsters in each group, respectively 

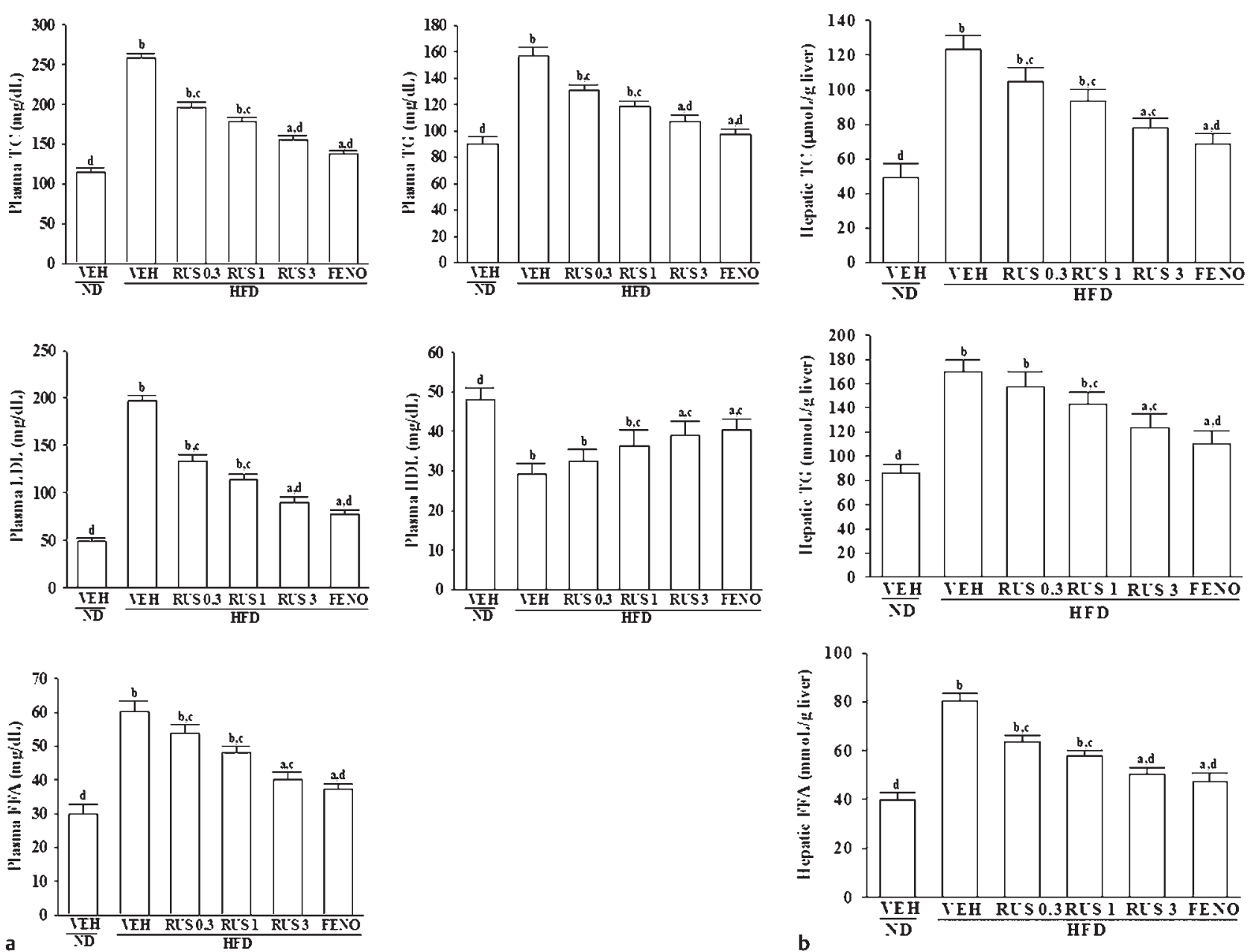

Fig. 2 Changes of lipid profile and FFA in plasma (A) and livers (B) of ND- or HFD-fed hamsters receiving eight weeks of treatments. HFD-fed hamsters were dosed by oral gavage once daily for eight weeks with $0.3 \mathrm{mg} / \mathrm{kg}$ ruscogenin (RUS 0.3), $1.0 \mathrm{mg} / \mathrm{kg}$ RUS (RUS 1), $3.0 \mathrm{mg} / \mathrm{kg}$ RUS (RUS 3), or $100 \mathrm{mg} /$ $\mathrm{kg}$ fenofibrate (FENO). ND- or HFD-fed hamsters receiving vehicle treatment were administered the same volume of vehicle (VEH) used to prepare test medications. Data are expressed as the mean with S.D. ( $n=8$ per group) in each column. ${ }^{\mathrm{a}} \mathrm{P}<0.01$ and ${ }^{\mathrm{b}} \mathrm{p}<0.01$ compared to vehicle-treated ND-fed hamsters in each group, respectively. ${ }^{c} \mathrm{P}<0.05$ and ${ }^{\mathrm{d}} \mathrm{p}<0.01$ compared to the values of vehicle-treated HFD-fed hamsters in each group, respectively. and $35.5 \%$, respectively) in fenofibrate-treated HFD-fed hamsters compared with their vehicle-treated counterparts ( $\bullet$ Fig. 2B). The hepatic FFA levels were significantly increased in hamsters fed an HFD, which were decreased by $37.3 \%$ and $41.2 \%$ in HFD-fed hamsters treated with ruscogenin $(3.0 \mathrm{mg} / \mathrm{kg} /$ day $)$ and fenofibrate, respectively ( $\bullet$ Fig. 2 B).

Representative histological photomicrographs of liver specimens are shown in $\odot$ Fig. 3. Hamsters fed a ND had normal liver histological findings; however, numerous macrovascular fat droplets and mild necroinflammatory foci were present in the livers of those fed an HFD. The treatment of HFD-fed hamsters with ruscogenin (3.0 mg/kg/day) or fenofibrate reduced fat liver depots and macrovesicular steatosis (๑ Fig. 3). Ruscogenin $(3.0 \mathrm{mg} / \mathrm{kg} / \mathrm{day})$ or fenofibrate treatment clearly reduced hepatic necroinflammation in HFD-fed hamsters ( Fig. 3). Histological grading of liver sections confirmed that ruscogenin $(3.0 \mathrm{mg} / \mathrm{kg} / \mathrm{day})$ or fenofibrate supplementation significantly ameliorated both hepatic steatosis and necroinflammation ( Table 2).

Plasma glucose and insulin concentrations as well as the homeostasis model assessment of insulin resistance (HOMA-IR) were higher in vehicle-treated HFD-fed hamsters than those in the ve- hicle-treated ND-fed group ( Fig. 4). After eight weeks of treatment with ruscogenin $(3.0 \mathrm{mg} / \mathrm{kg} /$ day $)$, plasma glucose concentrations were approximately $9.3 \%$ lower in HFD-fed hamsters compared with their vehicle-treated counterparts; corresponding plasma insulin and HOMA-IR values were $27.7 \%$ and $33.2 \%$ lower, respectively ( $\bullet$ Fig. 4). After eight weeks of treatment with fenofibrate, plasma glucose, plasma insulin, and HOMA-IR values were $7.6 \%, 32.5 \%$, and 38.4\% lower, respectively, in HFD-fed hamsters compared with their vehicle-treated counterparts ( $\bullet$ Fig. 4). The hepatic levels of monocyte chemoattractant protein (MCP)-1, TNF- $\alpha$, and interleukin (IL)- 6 in HFD-fed hamsters were significantly higher (2.4-, 2.3-, and 2.9-fold, respectively) than those of the ND-fed group ( Fig.5). Administration of ruscogenin (3.0 $\mathrm{mg} / \mathrm{kg} /$ day) to HFD-fed hamsters for eight weeks significantly downregulated the hepatic levels of MCP-1, TNF- $\alpha$, and IL-6 to $51.1 \%, 63.3 \%$, and $53.3 \%$, respectively, compared with those in the vehicle-treated counterparts ( Fig. 5). Fenofibrate treatment reversed the HFD-induced increase of hepatic levels of MCP-1, TNF- $\alpha$, and IL- 6 to $36.1 \%, 57.0 \%$ and $44.9 \%$, respectively, compared with their vehicle-treated counterparts ( $\bullet$ Fig. 5 ). 

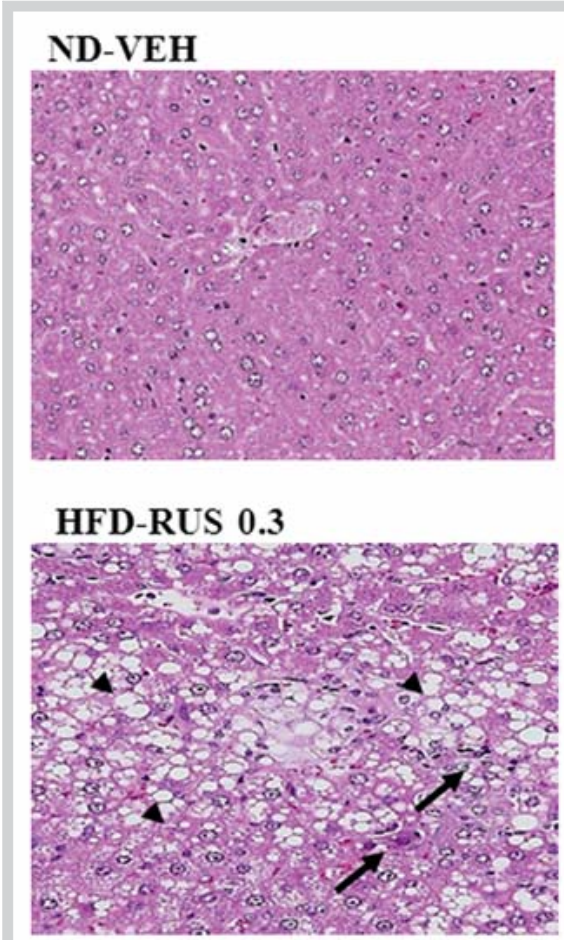

\section{HFD-RUS 3}

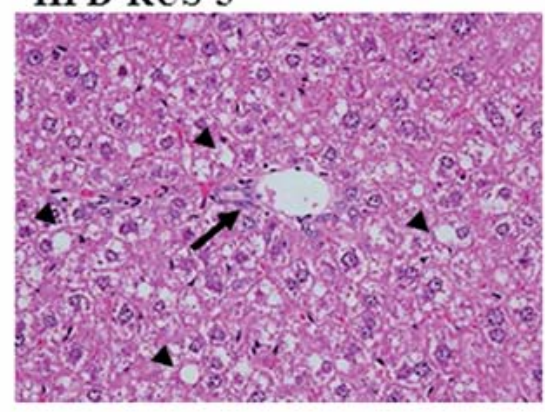

\section{HFD-VEH}

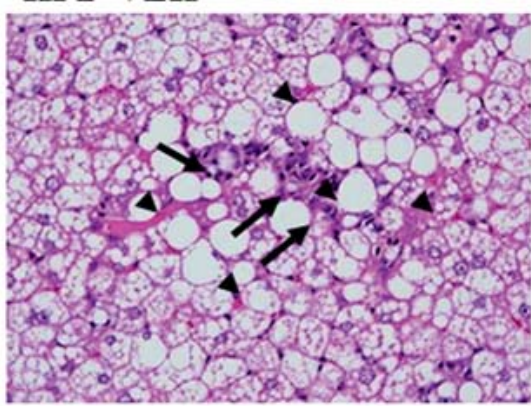

HFD-RUS 1

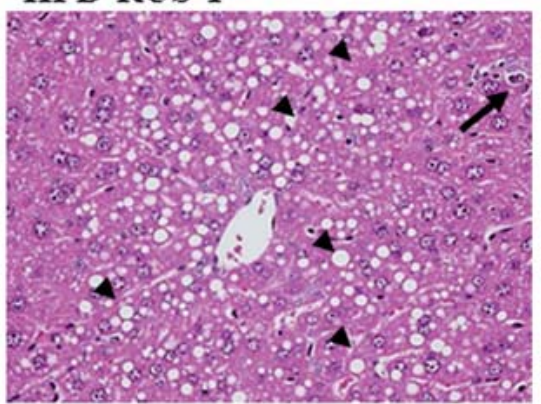

\section{HFD-FENO}

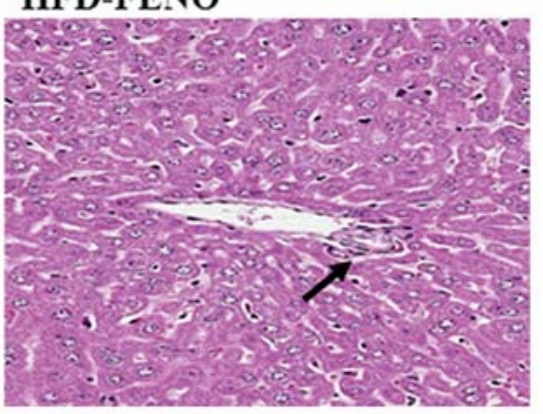

Fig. 3 Representative H\&E-stained photomicrographs (original magnification, 200×) of livers obtained from ND- or HFD-fed hamsters receiving eight weeks of treatments. HFD-fed hamsters were dosed by oral gavage once daily for eight weeks with $0.3 \mathrm{mg} / \mathrm{kg}$ ruscogenin (HFD-RUS 0.3), $1.0 \mathrm{mg} /$ kg RUS (HFD-RUS 1), $3.0 \mathrm{mg} / \mathrm{kg}$ RUS (HFD-RUS 3), or $100 \mathrm{mg} / \mathrm{kg}$ fenofibrate (HFD-FENO). ND- or HFD-fed hamsters receiving vehicle treatment were administered the same volume of vehicle (VEH) used to prepare test medications. Arrowhead and arrows indicate fat droplets and necroinflammatory foci, respectively. A summary of steatosis and necroinflammation scores in all groups is shown in - Table 2. (Color figure available online only.)

Table 2 Summary of steatosis and necroinflammation scores of ND- or HFD-fed hamsters receiving eight weeks of treatment.

\begin{tabular}{|c|c|c|c|c|c|c|}
\hline & \multirow{3}{*}{$\begin{array}{l}\text { ND-fed } \\
\text { Vehicle }\end{array}$} & \multicolumn{5}{|l|}{ HFD-fed } \\
\hline & & \multirow[t]{2}{*}{ Vehicle } & \multicolumn{3}{|c|}{ Ruscogenin (mg/kg/day) } & \multirow{2}{*}{$\begin{array}{l}\text { Fenofibrate } \\
(100 \mathrm{mg} / \mathrm{kg} / \text { day })\end{array}$} \\
\hline & & & 0.3 & 1.0 & 3.0 & \\
\hline \multicolumn{7}{|c|}{ Steatosis } \\
\hline 0 & 8 & 0 & 0 & 0 & 0 & 0 \\
\hline 1 & 0 & 0 & 1 & 2 & 4 & 5 \\
\hline 2 & 0 & 5 & 5 & 6 & 4 & 3 \\
\hline 3 & 0 & 3 & 2 & 0 & 0 & 0 \\
\hline 4 & 0 & 0 & 0 & 0 & 0 & 0 \\
\hline \multicolumn{7}{|c|}{ Necroinflammation } \\
\hline 0 & 8 & 0 & 0 & 0 & 0 & 1 \\
\hline 1 & 0 & 4 & 5 & 6 & 6 & 7 \\
\hline 2 & 0 & 3 & 2 & 1 & 2 & 0 \\
\hline 3 & 0 & 1 & 1 & 1 & 0 & 0 \\
\hline
\end{tabular}

There were eight animals in each group. Data are expressed as the number of hamsters exhibiting the grade of steatosis or necroinflammation indicated

An HFD significantly increased NF- $k$ B activity (by 3.2-fold relative to that of the vehicle-treated ND-fed group) in the livers of hamsters ( Fig. 6A). The HFD-induced upregulation of NF- $k$ B activity was reduced $39.1 \%$ and $48.1 \%$ relative to that of the HFD-fed hamsters after eight weeks of treatment with ruscogenin $(3.0 \mathrm{mg} / \mathrm{kg} /$ day) or fenofibrate, respectively ( $\odot$ Fig. 6A).

The phosphorylation degree of hepatic NF- $k$ B in HFD-fed hamsters was also higher by 2.5 -fold relative to their vehicle-treated 


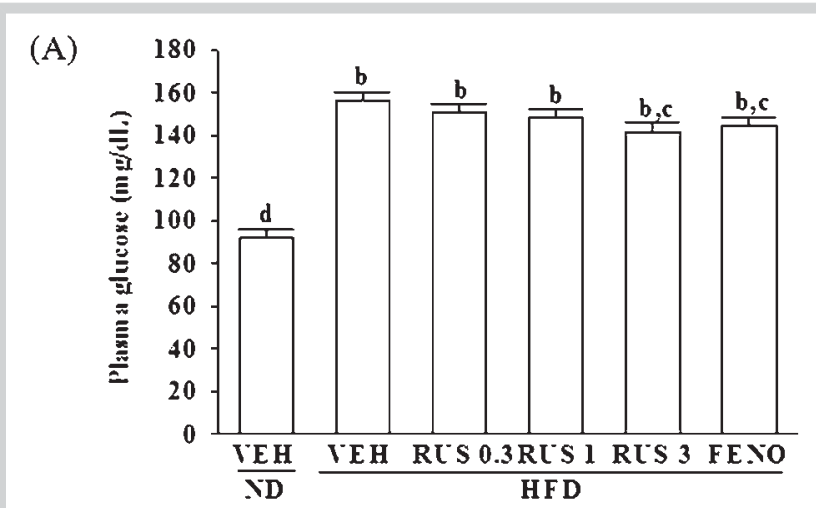

(B)

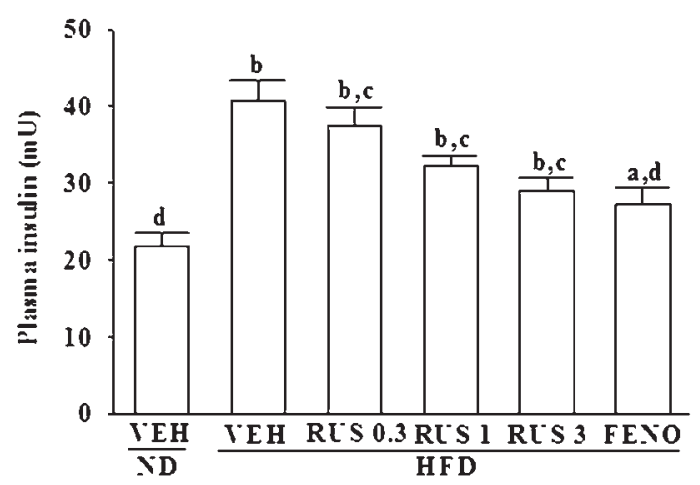

(C)

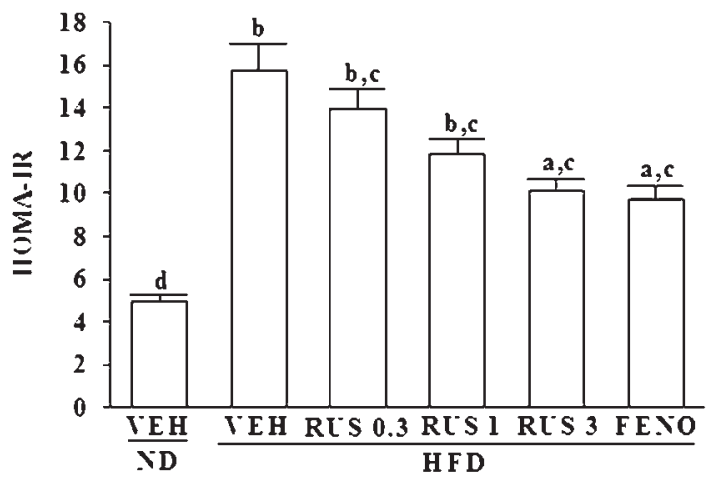

Fig. 4 Changes of plasma glucose (A), plasma insulin (B), and HOMA-IR (C) in ND- or HFD-fed hamsters receiving eight weeks of treatments. HFD-fed hamsters were dosed by oral gavage once daily for eight weeks with $0.3 \mathrm{mg} / \mathrm{kg}$ ruscogenin (RUS 0.3 ), $1.0 \mathrm{mg} / \mathrm{kg}$ ruscogenin (RUS 1), $3.0 \mathrm{mg} / \mathrm{kg}$ ruscogenin (RUS 3), or $100 \mathrm{mg} / \mathrm{kg}$ fenofibrate (FENO). ND- or HFD-fed hamsters receiving vehicle treatment were administered the same volume of vehicle (VEH) used to prepare test medications. Data are expressed as the mean with S. D. ( $n=8$ per group) in each column. ${ }^{a} \mathrm{P}<0.05$ and ${ }^{b} \mathrm{p}<0.01$ compared to vehicle-treated ND-fed hamsters in each group, respectively. ${ }^{c} P<0.05$ and ${ }^{d} p<0.01$ compared to the values of vehicletreated HFD-fed hamsters in each group, respectively.

counterparts ( $\mathbf{O}$ Fig. 6B). Treatment for eight weeks with ruscogenin $(3.0 \mathrm{mg} / \mathrm{kg} /$ day $)$ or fenofibrate decreased phosphorylated NF- $k$ B in the livers of HFD-fed hamsters to $59.3 \%$ and $49.1 \%$, respectively, relative to the vehicle-treated controls ( 0 Fig. 6B).

An HFD markedly increased the hepatic mRNA levels of sterol regulatory element-binding protein (SREBP)-1c in hamsters 3.2fold relative to those in the ND-fed group ( $\odot$ Fig. $7 \mathrm{~A}$ ). Ruscogenin $(3.0 \mathrm{mg} / \mathrm{kg} /$ day) suppressed the HFD-induced stimulation in hepatic mRNA levels of SREBP-1c to $63.5 \%$ relative to those in the

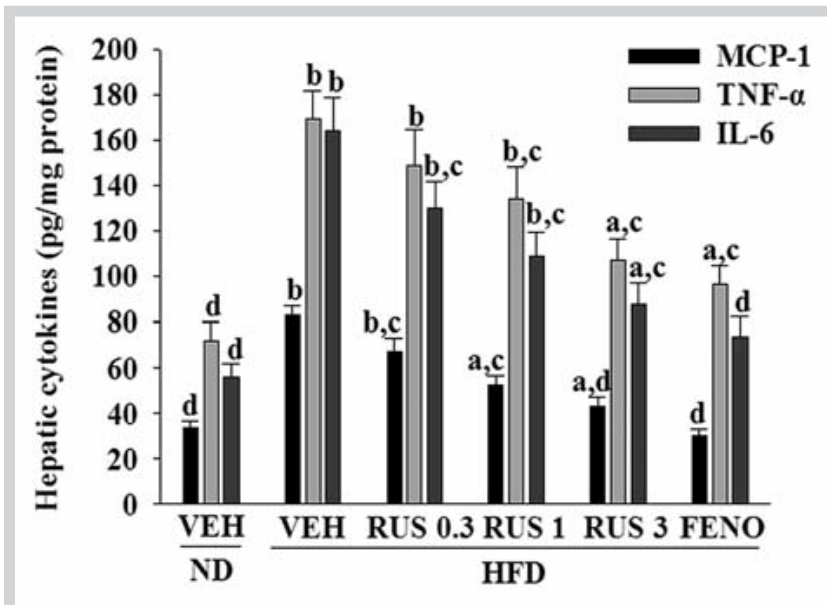

Fig. 5 Hepatic levels of cytokines in ND- or HFD-fed hamsters receiving eight weeks of treatment. HFD-fed hamsters were dosed by oral gavage once daily for eight weeks with $0.3 \mathrm{mg} / \mathrm{kg}$ ruscogenin (RUS 0.3 ), $1.0 \mathrm{mg} / \mathrm{kg}$ ruscogenin (RUS 1), $3.0 \mathrm{mg} / \mathrm{kg}$ ruscogenin (RUS 3), or $100 \mathrm{mg} / \mathrm{kg}$ fenofibrate (FENO). ND- or HFD-fed hamsters receiving vehicle treatment were administered the same volume of vehicle (VEH) used to dissolve test medications. Data are expressed as the mean with S. D. ( $n=8$ per group) in each column. ${ }^{\mathrm{a}} \mathrm{P}<0.05$ and ${ }^{\mathrm{b}} \mathrm{p}<0.01$ compared to vehicle-treated ND-fed hamsters in each group, respectively. ${ }^{c} \mathrm{P}<0.05$ and ${ }^{\mathrm{d}} \mathrm{p}<0.01$ compared to the values of vehicle-treated HFD-fed hamsters in each group, respectively.

vehicle-treated group (O Fig.7A). Hepatic mRNA levels of SREBP-1c were reduced (by 46.9\%) in fenofibrate-treated HFD-fed hamsters compared with their vehicle-treated counterparts ( $\odot$ Fig. 7 A).

An HFD caused a 2.8-fold induction of hepatic acetyl-CoA carboxylase (ACC) mRNA and a 2.5-fold induction of hepatic fatty acid synthase (FAS) mRNA relative to those in the ND-fed group. The hepatic mRNA levels of ACC and FAS were downregulated by ruscogenin $(3.0 \mathrm{mg} / \mathrm{kg} /$ day $)$ treatment, with a decrease of $23.5 \%$ and $36.7 \%$, respectively, when compared with those observed in the vehicle-treated group ( $\odot$ Fig. 7 A). The HFD-induced mRNA levels of ACC and FAS in the liver were reversed after fenofibrate treatment (a $48.6 \%$ and $47.1 \%$ decrease, respectively) compared to those in the vehicle-treated group ( $\bigcirc$ Fig. $7 \mathrm{~A}$ ).

The mRNA levels of peroxisome proliferator-activated receptor (PPAR) $\alpha$ in the livers of HFD-fed hamsters were lowered to $55.1 \%$ compared with those from the ND-fed group (O Fig. 7B). HFD-fed hamsters administered ruscogenin $(3.0 \mathrm{mg} / \mathrm{kg} /$ day $)$ or fenofibrate for eight weeks upregulated the hepatic PPAR $\alpha$ mRNA levels to 1.6- and 1.7-fold relative to those in the vehicle-treated group, respectively ( 0 Fig. 7B).

Compared with the ND-fed group, the hepatic mRNA levels of carnitine palmityl transferase (CPT)- 1 and acyl-CoA oxidase (ACO) in HFD-fed hamsters decreased obviously, and were upregulated by fenofibrate treatment (a 1.9- and 2.3-fold increase, respectively). The hepatic mRNA levels of CPT-1 and ACO in HFD-fed hamsters receiving ruscogenin $(3.0 \mathrm{mg} / \mathrm{kg} / \mathrm{day})$ supplementation were increased 1.6- and 2.0-fold relative to the expression levels in their vehicle-treated counterparts, respectively (O Fig. 7B). 


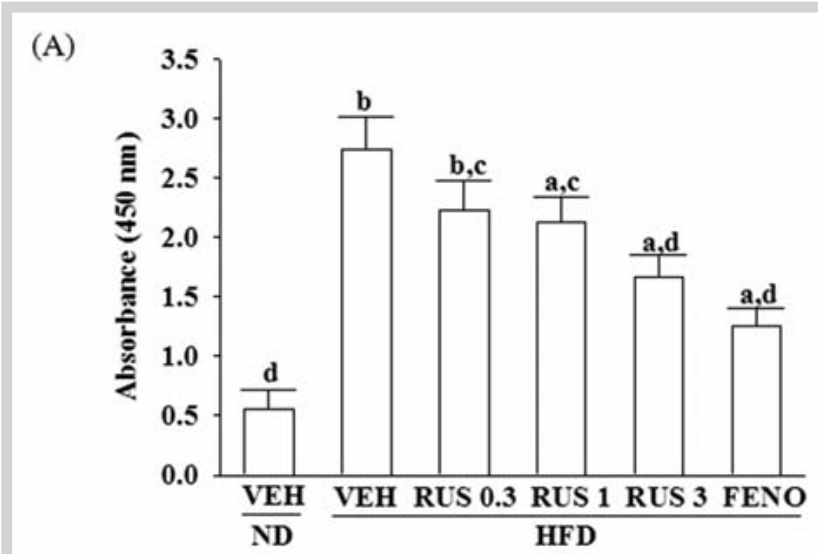

(B)
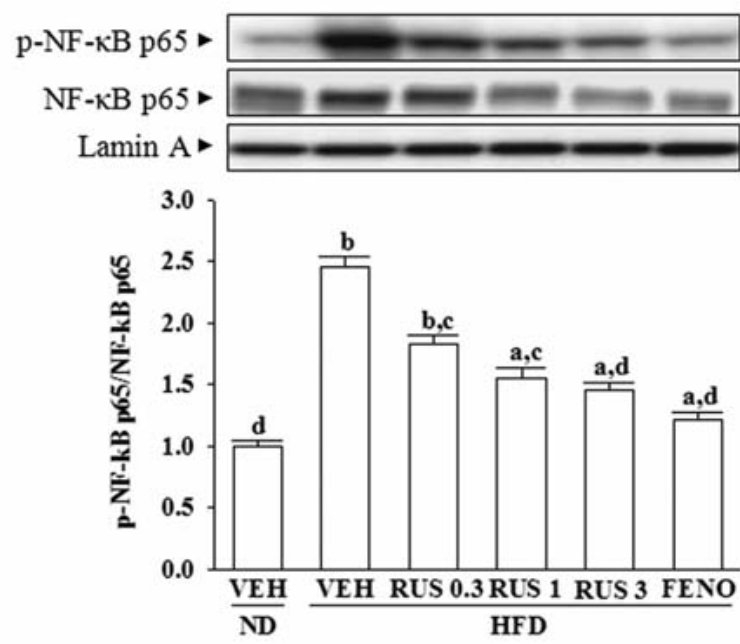

Fig. 6 The effects of treatments on NF-kB activity (A) and phosphorylated $\mathrm{NF}-\mathrm{KB}$ (B) in livers from ND- or HFD-fed hamsters receiving eight weeks of treatment. HFD-fed hamsters were dosed by oral gavage once daily for eight weeks with $0.3 \mathrm{mg} / \mathrm{kg}$ ruscogenin (RUS 0.3 ), $1.0 \mathrm{mg} / \mathrm{kg}$ ruscogenin (RUS 1), $3.0 \mathrm{mg} / \mathrm{kg}$ ruscogenin (RUS 3), or $100 \mathrm{mg} / \mathrm{kg}$ fenofibrate (FENO). ND- or HFD-fed hamsters receiving vehicle treatment were administered the same volume of vehicle (VEH) used to prepare test medications. The mean density values of $\mathrm{p}-\mathrm{NF}-\mathrm{KB}$ are expressed as ratios relative to that of $\mathrm{NF}-\mathrm{KB}$. The level of lamin A was estimated for equal loading of the nuclear sample. Similar results were obtained from an additional three replications. Data are expressed as the mean with S. D. ( $n=5$ per group) in each column. a $\mathrm{P}<0.05$ and ${ }^{\mathrm{b}} \mathrm{p}<0.01$ compared to vehicle-treated ND-fed hamsters in each group, respectively. ${ }^{c} \mathrm{P}<0.05$ and ${ }^{\mathrm{d}} \mathrm{p}<0.01$ compared to vehicletreated HFD-fed hamsters in each group, respectively.

\section{Discussion}

$\nabla$

In our model, HFD-fed hamsters developed hepatic steatosis, visceral obesity, hyperlipidemia, and increased FFA and HOMA-IR values, mimicking almost all of the clinical features of human NAFLD [12]. Fenofibrate, a fibric acid derivative, is a commercially available drug in the management of hyperlipidemia and NAFLD [13]. Fenofibrate was used to compare the efficacy of ruscogenin. Similar to the effects of fenofibrate, we found that ruscogenin supplementation significantly decreased body and liver weights, and plasma and liver contents of TG, TC, and FFA. In addition, ruscogenin attenuated the development of HFD-induced hepatic

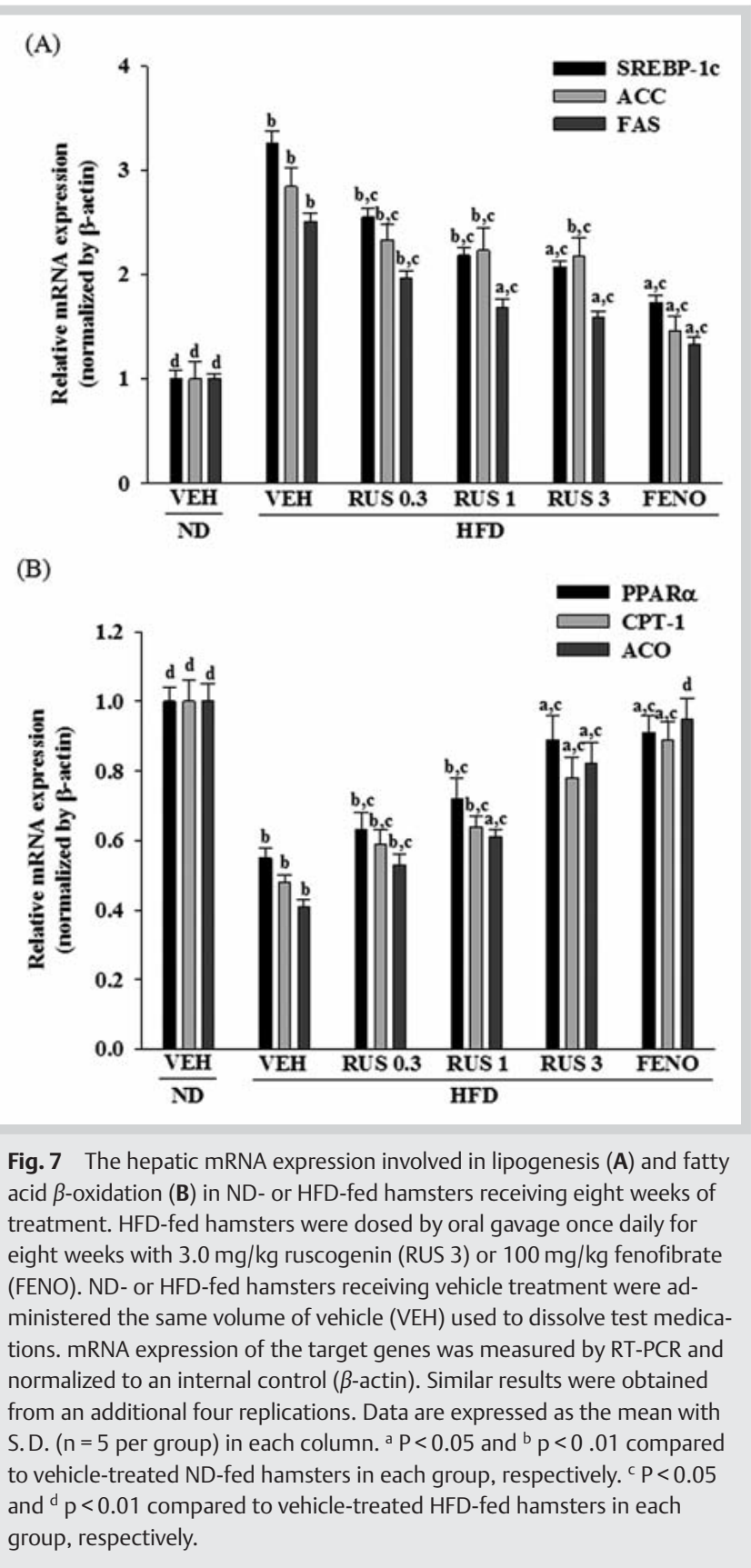

steatosis and injury as assessed by microscopic analysis. These data demonstrated that ruscogenin shows biological activity towards the regulation of lipid metabolism and steatosis development in the liver.

As inflammation plays a pivotal role in NAFLD, its modulation represents an important pharmacological target of inflammatory activation [14]. We therefore investigated whether ruscogenin could improve fatty liver changes by decreasing inflammatory cytokines in the HFD-induced NAFLD hamsters. Administration of ruscogenin during NAFLD development significantly attenuated the expression of MCP-1, TNF- $\alpha$, and IL-6 in the liver of HFD-fed hamsters. These data indicate that ruscogenin might be effective for preventing and reversing the inflammatory response, which may accelerate the lipid metabolism disorder and/or more severe liver injuries. Actually, these inflammatory cytokines are shown to be involved in the development of insulin resistance [15]. We 
observed that not only hyperinsulinemia but also higher HOMA-IR values were alleviated by ruscogenin treatment in HFD-fed hamsters. These results further suggest that ruscogenin could ameliorate fatty liver in the insulin-resistant state.

NF- $k$ B is a ubiquitous and well-known transcription factor, which undergoes phosphorylation on serine 276 in its p65 subunit and associates with surrounding chromatin components. It subsequently binds with DNA and promotes the transcription of proinflammatory cytokines, chemokines, and adhesion molecules [16]. Thus, detection of the phosphorylated p65 subunit of NF$\kappa \mathrm{B}$ was effective for evaluating NF- $k \mathrm{~B}$ activation [17]. Ruscogenin has been reported to have anti-inflammatory activity through inhibiting NF- $k$ B activity $[10,11]$. The inhibition of NF- $k$ B by ruscogenin might be a critical step for prevention of the cascading inflammatory response during NAFLD development. In the present study, ruscogenin significantly inhibited hepatic NF- $k$ B activation in HFD-fed hamsters, as evidenced by a decrease in NF- $k$ B activity and downregulation of phosphorylated NF- $k \mathrm{~B}$. These results suggest that ruscogenin inhibits the activation of NF- $k$ B, leading to the downregulation of inflammatory mediators and, therefore, shows a promising effect in preventing NAFLD. Whether ruscogenin can directly target NF- $k$ B or act as the upstream signaling molecules for its activation requires further investigation.

To explore the possible mechanisms whereby ruscogenin decreases hepatic lipid accumulation, we then investigated the expression levels of several genes related to lipid metabolism, including lipogenesis and $\beta$-oxidation. SREBP-1c has been shown to regulate the transcription of genes in the lipogenic pathway including ACC and FAS [17]. Liver-specific ACC knockout mice showed a decreased hepatic triglyceride accumulation, suggesting that ACC plays a crucial role in the regulation of lipogenesis [18]. FAS catalyzes the last step in fatty acid biosynthesis and is thus believed to be a major determinant of the maximal hepatic capacity to generate fatty acids by de novo lipogenesis [19]. Low levels of SREBP-1c mRNA in the livers of HFD-fed hamsters receiving ruscogenin were accompanied by a concomitant reduction in the expression of ACC and FAS mRNA. Ruscogenin is thus likely to have an inhibitory effect on SREBP-1c expression, which in turn decreases transcription of its target lipogenic genes, thereby reducing enzyme activity and resulting in a low rate of lipid synthesis. Ruscogenin appeared to mediate its beneficial effects on HFD-induced hepatic steatosis by downregulating expression of hepatic genes related to lipid synthesis.

PPAR $\alpha$ mediates $\beta$-oxidation of fatty acids, and agonists of PPAR $\alpha$ possess the property of reducing lipid dystrophy and obesity [20]. PPAR $\alpha$ activates some of the key enzymes of $\beta$-oxidation and $\beta$-oxidation of fatty acids in the liver [21]. HFD-fed hamsters displayed a reduced expression of PPAR $\alpha$ in the liver. A multitude of studies have postulated that during diet-induced obesity, fatty acid oxidation is left incomplete accompanied by mitochondrial lipid overload and dysfunction. To explore whether the effect of ruscogenin on the attenuation of HFD-induced hepatic steatosis was related to the PPAR $\alpha$-mediated pathway, mRNA expression of PPAR $\alpha$ and its target genes responsible for $\beta$-oxidation of fatty acids was measured. Ruscogenin markedly increased the HFD-induced low expression of hepatic PPAR $\alpha$ mRNA. Furthermore, ruscogenin treatment upregulated the PPAR $\alpha$-mediated transcription of CPT-1 and ACO mRNA in the liver of HFD-fed hamsters. CPT- 1 and ACO are major enzymes that catalyze fatty acid $\beta$-oxidation and are responsive to PPAR $\alpha$ activation [22,23]. The similar trend in expression among these genes suggests that ruscoge- nin enhanced $\beta$-oxidation of fatty acids via the pathway involving PPAR $\alpha$-mediated gene transcription.

ALT and AST are considered to be sensitive indicators of hepatocellular damage and, within limits, can provide a quantitative evaluation of the degree of damage to the liver [24]. We found that the ALT and AST activities were markedly reduced in HFD-fed hamsters treated for eight weeks with ruscogenin. It seems that animals treated with ruscogenin at the chosen doses exhibited no evidence of hepatotoxicity. For a more reliable safety evaluation performed on the basis of the acceptable daily intake concept, data on the chronic toxicity, reproductive toxicity, genotoxicity, and carcinogenicity of ruscogenin would also be required.

In conclusion, the results of this study demonstrated that ruscogenin exerted a protective effect on HFD-induced hepatic steatosis in hamsters by modulating lipid metabolism-associated genes. It is also possible that the inhibition of NF- $k$ B activation thereby led to the downregulation of inflammatory mediators and this is integral to the protective functions of ruscogenin in HFD-induced hepatocellular injury and its subsequent progression to steatohepatitis.

\section{Materials and Methods}

$\nabla$

\section{Animal models}

Male Golden Syrian hamsters, eight weeks old and weighing $90 \pm 10 \mathrm{~g}$, were obtained from the National Laboratory Animal Center. They were maintained in a temperature-controlled room $\left(25 \pm 1{ }^{\circ} \mathrm{C}\right)$ on a 12 -h:12-h light-dark cycle (lights on at $06: 00 \mathrm{~h}$ ) in our animal center. Food and water were provided ad libitum. An ND (\#D12450B, Research Diets) with $20 \mathrm{kcal} \%$ protein, $70 \mathrm{kcal} \%$ carbohydrate, and $10 \mathrm{kcal} \%$ fat from lard was used as the maintenance and control diet. A purified ingredient HFD with $20 \mathrm{kcal} \%$ protein, $35 \mathrm{kcal} \%$ carbohydrate, and $45 \mathrm{kcal} \%$ fat primarily from lard (\#D12451, Research Diets) was used to induce weight gain [25]. All animal procedures were performed according to the Guide for the Care and Use of Laboratory Animals of the National Institutes of Health, as well as the guidelines of the Animal Welfare Act. These studies were conducted with the approval of the Institutional Animal Care and Use Committee (IACUC) at Tajen University (approval number, IACUC 101-16; approval date, December 24, 2012).

\section{Treatment protocols}

After being fed an HFD for two weeks, hamsters were dosed by oral gavage once per day for eight weeks with ruscogenin (doses of $0.3,1.0$ or $3.0 \mathrm{mg} / \mathrm{kg}$ ) in a volume of $1.5 \mathrm{~mL} / \mathrm{kg}$ distilled water. The dosage regime was selected based on a previous report demonstrating that ruscogenin ( $\geq 98 \%$; Chengdu Biopurify Phytochemicals Ltd.; Cat. No.472-11-7) at the indicated dosage regimen was potentially effective in inhibiting inflammation in mice [11]. Another group of HFD-fed hamsters was treated orally for eight weeks with $100 \mathrm{mg} / \mathrm{kg} /$ day fenofibrate (isopropyl 2-[4(4-chlorobenzoyl)phenoxy]-2-methylpropionate; Laboratories Fournier SA) with a purity greater than $99.5 \%$. Two g of powdered fenofibrate was dissolved in $20 \mathrm{ml}$ of distilled water, so that $1 \mathrm{ml}$ will contain $100 \mathrm{mg}$ of fenofibrate. The dose of fenofibrate was based on a study reporting that long-term fenofibrate treatment could ameliorate hepatic insulin resistance and steatosis in highfructose-fed mice [26]. The control groups received water by gavage instead of ruscogenin or fenofibrate. Water consumption, 
food intake, and body weight were measured individually at the same time $(09: 00 \mathrm{~h})$ on each day throughout the experiment. Food cups containing fresh food were weighed at the beginning and end of each 24 -h period. Food intake was calculated by determining the difference in food cup weights, adjusting for any spillage that occurred. Water intake was calculated by measuring the difference in water bottle weights at the beginning and end of the daily change of water.

After eight weeks of treatment, animals were weighed and sacrificed by being deeply anesthetized with ketamine $(50-75 \mathrm{mg} / \mathrm{kg}$ ) after fasting for 12 hours. Blood samples were taken from the inferior vena cava for analysis. After blood collection, the left lobe of the liver, and visceral and subcutaneous white adipose tissue (WAT) were removed, rinsed with a physiological saline solution, and immediately stored at $-80^{\circ} \mathrm{C}$ in liquid nitrogen until assayed. The hepatic weight coefficient was also calculated as liver weight (g) divided by body weight (100 g). The right hepatic lobe was fixed in $10 \%$ neutralized formalin for histology.

\section{Determination of plasma biochemical parameters and insulin sensitivity}

Blood samples were centrifuged at $2000 \times \mathrm{g}$ for $10 \mathrm{~min}$ at $4^{\circ} \mathrm{C}$. The plasma was then removed and placed into aliquots for the respective analyses. Kits for determining plasma glucose (Cat. No.10009582) concentration was purchased from Cayman Chemical Company. Commercial enzyme-linked immunosorbent assay (ELISA) kits were used to quantify plasma insulin concentration (LINCO Research, Inc.; Cat. \# EZRMI-13K). Whole-body insulin sensitivity was estimated using HOMA-IR with the following formula: [fasting plasma glucose $(\mathrm{mmol}) \times$ fasting plasma insulin $(\mathrm{mU} / \mathrm{mL})] / 22.5$ [27]. Diagnostic kits for determination of plasma levels of TC (Cat. \# 10007640) and TG (Cat. \# 10010303) were purchased from Cayman Chemical Company. The diagnostic kit for determination of plasma levels of HDL-C was purchased from Bio-Quant Diagnostics (Cat. \# BQ 019CR). LDL-C concentrations in plasma were determined by a commercial ELISA kit (antibodies-online, Inc.; Cat. \# ABIN416222). The plasma FFA level was determined using an FFA quantification kit obtained from Abcam plc (Cat. \# ab65341). Kits for determination of plasma ALT (EC 2.6.1.2) (Cat. No. A524-780TM) and AST (EC 2.6.1.1) (Cat. No. A559-780TM) concentrations were purchased from Teco Diagnostics. All analyses were performed in triplicate in accordance with the manuals provided by the manufacturers.

\section{Measurement of hepatic lipids}

Liver tissue $(0.5 \mathrm{~g})$ was homogenized for $5 \mathrm{~min}$ in $1 \mathrm{~mL}$ of ice-cold phosphate-buffered saline (PBS) using a tissue homogenizer (T10 basic Ultra-Turrax; IKA Werke GmbH \& Co. KG). A 2-mL aliquot of chloroform/methanol $(2: 1, \mathrm{v} / \mathrm{v})$ was added to the homogenate and vortexed for $60 \mathrm{~s}$. After standing at $4{ }^{\circ} \mathrm{C}$ in the dark for $12 \mathrm{~h}$, the homogenate was centrifuged at $2300 \times \mathrm{g}$ for $15 \mathrm{~min}$. The bottom organic phase was dried under nitrogen gas and the residue was suspended in $1 \mathrm{~mL}$ of $3 \%$ Triton X-100, and an aliquot was used for the measurement of TG, TC, and FFA using the same commercial kits used for plasma analysis. Samples were assayed in triplicate according to the manufacturer's instructions.

\section{Hepatic cytokines determination}

Liver tissue $(0.5 \mathrm{~g}$ ) was homogenized with a teflon Potter-Elvejhem tissue homogenizer in $10 \mathrm{mmol} / \mathrm{L} \mathrm{Tris-HCl}$ buffered solution (pH 7.4) containing $2 \mathrm{~mol} / \mathrm{L} \mathrm{NaCl}, 1 \mathrm{mmol} / \mathrm{L}$ EDTA, $0.01 \%$ Tween 80 , and $1 \mathrm{mmol} / \mathrm{L} \mathrm{PMSF}$, and centrifuged at $9000 \times \mathrm{g}$ for $30 \mathrm{~min}$ at $4{ }^{\circ} \mathrm{C}$. The resultant supernatant was used for cytokine determination. ELISA kits for the determination of MCP-1 (Cat. No. ab100777), TNF $\alpha$ (Cat. No. ab46070), and IL-6 (Cat. No. ab100772) were obtained from Abcam, Inc. Samples were assayed in triplicate according to the manufacturer's instructions. The protein concentrations of liver filtrate were determined using a Bio-Rad protein assay kit (Bio-Rad Laboratories) and bovine serum albumin (BSA) as a standard.

\section{Hepatic histology}

After the liver samples were fixed in $10 \%$ formalin solution at room temperature, they were processed by the standard method. Briefly, tissues were embedded in paraffin, sectioned at $5 \mu \mathrm{m}$, and stained with hematoxylin and eosin (H\&E), and then picked up on glass slides for light microscopy. All samples were evaluated by an experienced pathologist who was blinded to the experiment. A semiquantitative scoring system was used to assess the severity of hepatic steatosis and necroinflammation in $10 \mathrm{mi}-$ croscopic fields examined at 200× magnification as described previously [28]. Steatosis was scored as the percentage of parenchymal cells containing fat: $0=$ no parenchymal cells containing fat, $1=<20 \%$ of parenchymal cells containing fat, $2=20-39 \%$ of parenchymal cells containing fat, $3=40-50 \%$ of parenchymal cells containing fat, and $4=>51 \%$ of parenchymal cells containing fat. Inflammation and necrosis were scored by the number of foci of inflammation and necrosis identified under a low-power field of a light microscope: 0 = no inflammation and necrosis, $1=1$ focus of inflammation and necrosis per low-power field, $2=2$ foci of inflammation and necrosis per low-power field, and $3=3$ foci of inflammation and necrosis per low-power field.

\section{Nuclear transcription factor-кB activity measurement}

Nuclear extracts of livers from the above-mentioned groups were prepared using the nuclear extraction kit (Active Motif; Cat. No. 40010). In brief, the liver ( $0.5 \mathrm{~g}$ ) was pulverized under liquid nitrogen. Powdered tissue was suspended in hypotonic buffer containing a protease inhibitor cocktail, phosphatase inhibitors, DTT, and detergent (Active Motif). Samples were dounce homogenized, incubated on ice for $15 \mathrm{~min}$, and then centrifuged $\left(850 \times \mathrm{g}, 10 \mathrm{~min}, 4^{\circ} \mathrm{C}\right)$.

The pellet was suspended in hypotonic buffer containing detergent and then centrifuged $\left(14000 \times \mathrm{g}, 30 \mathrm{~s}, 4^{\circ} \mathrm{C}\right)$. The resulting pellet was suspended in lysis buffer and incubated on ice for $30 \mathrm{~min}$, and then nuclear extracts were obtained by centrifugation $\left(14000 \times \mathrm{g}, 10 \mathrm{~min}, 4^{\circ} \mathrm{C}\right)$. Twenty micrograms of nuclear extract were used for the determination of NF- $k$ B activity with the TransAM ${ }^{\circledR}$ NF- $k$ B p 65 transcription factor assay kit (Active Motif; Cat. No.40096), according to the manufacturer's instruction.

\section{Western blotting}

Liver tissues were homogenized in $1 \mathrm{ml}$ of ice-cold hypotonic buffer A [10 mmol/L HEPES (pH 7.8), 10 mmol/L KCl, 2 mmol/L $\mathrm{MgCl}_{2}, 1 \mathrm{mmol} / \mathrm{L}$ DTT, $0.1 \mathrm{mmol} / \mathrm{L}$ EDTA, $0.1 \mathrm{mmol} / \mathrm{L}$ phenylmethylsulfonylfluoride]. The cells were then lysed with $12.5 \mu \mathrm{L} 10 \%$ Nonidet P-40. The homogenate was centrifuged and the supernatant containing the cytoplasmic extracts was stored frozen at $-80^{\circ} \mathrm{C}$. The nuclear pellet was resuspended in $25 \mu \mathrm{L}$ ice-cold nuclear extraction buffer. After 30 min of intermittent mixing, the extract was centrifuged, and the supernatants containing nuclear extracts were secured.

Before immunoblotting, the protein concentration of each tissue was determined using a Bio-Rad protein assay kit (Bio-Rad Labo- 
ratories) and BSA as a standard, to ensure equal loading among lanes. Nuclear extracts ( $50 \mu \mathrm{g}$ total protein) were separated on a $7.5-15 \%$ polyacrilamide gel and electophoretically transferred to a nitrocellulose membrane. Membranes were blocked with 5\% nonfat dry milk in Tris-buffered saline Tween $(20 \mathrm{mmol} / \mathrm{L}$ Tris, $\mathrm{pH} 7.6,137 \mathrm{mmol} / \mathrm{L} \mathrm{NaCl}$, and $0.1 \%$ Tween 20 ) for $3 \mathrm{~h}$ at room temperature, and incubated overnight at $4{ }^{\circ} \mathrm{C}$ with the following primary antibodies: p-NF- $k$ B p65 (Ser276) (Santa Cruz Biotechnology, Inc.; Cat. No. sc-101749) and NF-kB p65 (Cell Signaling Technology; Cat. No. 4764). The level of lamin A (Santa Cruz Biotechnology, Inc.; Cat. No. sc-20680) was estimated for equal loading of the nuclear sample. After washing three times with Trisbuffered saline Tween 20 (TBST), incubation with appropriate horseradish peroxidase-conjugated secondary antibodies was performed for $1 \mathrm{~h}$ at room temperature. After three additional TBST washes, the immunoreactive bands were visualized by enhanced chemiluminescence (Amersham Biosciences), according to the manufacturer's instructions. Band densities were determined using ATTO Densitograph Software (ATTO Corporation). All experimental sample values were then expressed relative to this adjusted mean value. Tissue sections were sampled from four independent experiments.

\section{Analysis of mRNA expression of hepatic genes}

Total RNA was extracted from $100 \mathrm{mg}$ frozen liver samples using Trizol reagent (Invitrogen). RNA was quantified by A260 and its integrity verified by agarose gel electrophoresis using ethidium bromide for visualization. For the reverse transcriptase reaction, $1 \mu \mathrm{g}$ of total RNA per sample and $8.5 \mu \mathrm{g} / \mu \mathrm{L}$ random hexamer primers were heated at $65^{\circ} \mathrm{C}$ for $5 \mathrm{~min}$ and then quenched on ice. This mixture was combined with $500 \mu \mathrm{mol} / \mathrm{L}$ each of dATP, dTTP, dCTP, and dGTP, $10 \mathrm{mmol} / \mathrm{L}$ DTT, $20 \mathrm{mmol} / \mathrm{L}$ Tris-HCl (pH 8.4), $50 \mathrm{mmol} / \mathrm{L} \mathrm{KCl}, 5 \mathrm{mmol} / \mathrm{L} \mathrm{MgCl}_{2}$, 40 units of RNaseOUTTM recombinant ribonuclease inhibitor (Invitrogen), and 100 units SuperScript III reverse transcriptase (Invitrogen). Samples were subjected to DNase (Promega) treatment at $37^{\circ} \mathrm{C}$ for $20 \mathrm{~min}$ in a GeneAmp 9700 Thermal Cycler (Applied Biosystems) and then held at $4{ }^{\circ} \mathrm{C}$. After the aliquots were taken for immediate use in $\mathrm{PCR}$, the remainder of the cDNA was stored at $-20^{\circ} \mathrm{C}$. mRNA expression was measured by quantitative real-time reverse transcription polymerase chain reaction (RT-PCR) in a fluorescent temperature Lightcycler 480 (Roche Diagnostics). The following primer sequences were used: 5'-TCAACAACCAAGACAGTGACTTCCCTGGCC-3' (forward) and 5'-GTTCTCCTGCTTGAGCTTCTGGTTGCTGTG-3' (reverse) for SREBP-1c; 5'-TCGTGGGCTACAGCATGGT-3' (forward) and 5'-GCCCTCTGAAGTCGAAGAAGAA-3' (reverse) for FAS; 5'-CTGTAGAAACCCGGACAGTAGAAC-3' (forward) and 5'-GGTCAGCATACATCTCCATGTG-3' (reverse) for ACC; 5'-CGTCCTGGCCTTCTAAACGTAG-3' (forward) and 5'-CCTGTAGATCTCCTGCAGTAGCG-3' (reverse) for PPAR $\alpha$; 5'-ATGGCAGAGGCTCACCAAGCTGTG-3' (forward) and 5'-CCTCTGTGGTACACAACAATGTGC-3' (reverse) for CPT-1; 5'-ACTATATTTGGCCAATTTTGTG-3' (forward) and 5'-TGTGGCAGTGGTTTCCAAGCC-3' (reverse) for ACO; 5'-TGTGATGGTGGGAATGGGTCAG-3' (forward), and 5'-TTTGATGTCACGCACGAT TTCC-3' (reverse) for $\beta$-actin. Primers were designed using Primer Express Software version 2.0 System (Applied Biosystems). The PCR reaction was performed using the following cycling protocol: $95^{\circ} \mathrm{C}$ for $5 \mathrm{~min}$, followed by 45 cycles of $95^{\circ} \mathrm{C}$ for $5 \mathrm{~s}, 58^{\circ} \mathrm{C}$ for $15 \mathrm{~s}$, and $72^{\circ} \mathrm{C}$ for $20 \mathrm{~s}$. Dissociation curves were run after amplification to identify the specific PCR products. The mRNA expression levels were normalized to $\beta$ - actin mRNA levels and calculated according to the delta-delta $\mathrm{Ct}$ method [29].

\section{Statistical analysis}

Data are expressed as the mean \pm standard deviation (S.D.). Statistical analysis was performed with one-way analysis of variance (ANOVA). Dunnett range post hoc comparisons were used to determine the source of significant differences, where appropriate. For the histological study, a nonparametric Kruskal-Wallis test was performed and Mann-Whitney's U test was used to compare data within the groups. The SigmaPlot (Version 11.0) program was used for statistical analysis. A p value $<0.05$ was considered statistically significant.

\section{Acknowledgements \\ $\nabla$}

The present study was supported by a grant from the National Science Council Grant (Grant No: NSC 102-2320-B-127-001MY3) of Taiwan.

\section{Conflict of Interest}

$\nabla$

No competing financial interests exist.

\section{References}

1 Neuschwander-Tetri BA, Caldwell SH. Nonalcoholic steatohepatitis: summary of an AASLD Single Topic Conference. Hepatology 2003; 37: 1202-1219

2 Asrih M, Jornayvaz FR. Inflammation as a potential link between nonalcoholic fatty liver disease and insulin resistance. J Endocrinol 2013; 218: R25-R36

3 Mittal S, El-Serag HB. Epidemiology of hepatocellular carcinoma: consider the population. J Clin Gastroenterol 2013; 47: S2-S6

4 Day CP, James OF. Steatohepatitis: a tale of two "hits"? Gastroenterology 1998; $114: 842-845$

$5 \mathrm{Yu} B Y$. Exploration on the modern research methodology of traditional Chinese medicine, basing on the systemic research of Radix Ophiopogon. Chin J Nat Med 2007; 5: 10-14

6 Bensky D, Clavey S, Stoger E, Gamble A. Chinese herbal medicine materia medica, third edition. Seattle: Eastland Press; 2004

7 Capra C. Pharmacology and toxicology of some components of Ruscus aculeatus. Fitoterapia 1972; 43: 99-113

8 Bouskela E, Cyrino FZ, Marcelon G. Possible mechanisms for the inhibitory effect of Ruscus extract on increased microvascular permeability induced by histamine in hamster cheek pouch. J Cardiovasc Pharmacol 1994; 24: 281-285

9 Kou JP, Tian YQ Tang YK, Yan J, Yu BY. Antithrombotic activities of aqueous extract from Radix Ophiopogon japonicus and its two constituents. Biol Pharm Bull 2006; 29: 1267-1270

10 Huang YL, Kou JP, Ma L, Song JX, Yu BY. Possible mechanism of the antiinflammatory activity of ruscogenin: role of intercellular adhesion molecule-1 and nuclear factor-kappaB. J Pharmacol Sci 2008; 108: 198-205

11 Sun $Q$ Chen L, Gao M, Jiang W, Shao F, Li J, Wang J, Kou J, Yu B. Ruscogenin inhibits lipopolysaccharide-induced acute lung injury in mice: involvement of tissue factor, inducible NO synthase and nuclear factor (NF)-kB. Int Immunopharmacol 2012; 12: 88-93

12 Bhathena J, Kulamarva A, Martoni C, Urbanska AM, Malhotra M, Paul A, Prakash S. Diet-induced metabolic hamster model of nonalcoholic fatty liver disease. Diabetes Metab Syndr Obes 2011; 4: 195-203

13 Kostapanos MS, Kei A, Elisaf MS. Current role of fenofibrate in the prevention and management of non-alcoholic fatty liver disease. World J Hepatol 2013; 5: 470-478

14 Braunersreuther V, Viviani GL, Mach F, Montecucco F. Role of cytokines and chemokines in non-alcoholic fatty liver disease. World J Gastroenterol 2012; 18: 727-735 
15 Kanda H, Tateya S, Tamori Y, Kotani K, Hiasa K, Kitazawa R, Kitazawa S, Miyachi H, Maeda S, Egashira K, Kasuga M. MCP-1 contributes to macrophage infiltration into adipose tissue, insulin resistance, and hepatic steatosis in obesity. J Clin Invest 2006; 116: 1494-1505

16 Guijarro C, Egido J. Transcription factor-kappa B (NF-kappa B) and renal disease. Kidney Int 2001; 59: 415-424

17 Osborne TF. Sterol regulatory element-binding proteins (SREBPs): key regulators of nutritional homeostasis and insulin action. J Biol Chem 2000; 275: 32379-32382

18 Mao J, DeMayo FJ, Li H, Abu-Elheiga L, Gu Z, Shaikenov TE, Kordari P, Chirala SS, Heird WC, Wakil SJ. Liver-specific deletion of acetyl-CoA carboxylase 1 reduces hepatic triglyceride accumulation without affecting glucose homeostasis. Proc Natl Acad Sci U S A 2006; 103: 8552-8557

19 Jensen-Urstad AP, Semenkovich CF. Fatty acid synthase and liver triglyceride metabolism: housekeeper or messenger? Biochim Biophys Acta 2012; 1821: 747-753

20 Rector RS, Payne RM, Ibdah JA. Mitochondrial trifunctional protein defects: clinical implications and therapeutic approaches. Adv Drug Deliv Rev 2008; 60: 1488-1496

21 Reddy JK, Hashimoto T. Peroxisomal beta-oxidation and peroxisome proliferator activated receptor alpha: an adaptive metabolic system. Annu Rev Nutr 2001; 21: 193-230

22 Bartlett K, Eaton S. Mitochondrial beta-oxidation. Eur J Biochem 2004; 271: 462-469
23 Poirier Y, Antonenkov VD, Glumoff T, Hiltunen JK. Peroxisomal beta-oxidation-a metabolic pathway with multiple functions. Biochim Biophys Acta 2006; 1763: 1413-1426

24 Giboney PT. Mildly elevated liver transaminase levels in the asymptomatic patient. Am Fam Physician 2005; 71: 1105-1110

25 Van Heek M, Compton DS, France CF, Tedesco RP, Fawzi AB, Graziano MP, Sybertz EJ, Strader CD, Davis jr. HR. Diet-induced obese mice develop peripheral, but not central, resistance to leptin. J Clin Invest 1997; 99: 385-390

26 Chan SM, Sun RQ Zeng XY, Choong ZH, Wang H, Watt MJ, Ye JM. Activation of PPAR $\alpha$ ameliorates hepatic insulin resistance and steatosis in high fructose-fed mice despite increased endoplasmic reticulum stress. Diabetes 2013; 62: 2095-2105

27 Matthews DR, Hosker JP, Rudenski AS, Naylor BA, Treacher DF, Turner RC. Homeostasis model assessment: insulin resistance and beta-cell function from fasting plasma glucose and insulin concentrations in man. Diabetologia 1985; 28: 412-419

28 Colantoni A, Idilman R, De Maria N, La Paglia N, Belmonte J, Wezeman F Emanuele N, Van Thiel DH, Kovacs EJ, Emanuele MA. Hepatic apoptosis and proliferation in male and female rats fed alcohol: role of cytokines. Alcohol Clin Exp Res 2003; 27: 1184-1189

29 Livak KJ, Schmittgen TD. Analysis of relative gene expression data using real-time quantitative PCR and the $2-\Delta \Delta C T$ method. Methods 2001; 25: $402-408$ 